\title{
Inhibin-A and inhibin-B in cyclic and pregnant mares, and mares with granulosa-theca cell tumors: Physiological and diagnostic implications
}

\section{A R T I C L E I N F O}

\section{Article history:}

Received 22 September 2017

Received in revised form

29 November 2017

Accepted 1 December 2017

Available online 7 December 2017

\section{Keywords:}

Inhibin-A

Inhibin-B

Equine

Cyclic

Ovarian tumor

\begin{abstract}
A B S T R A C T
Studies in mares have examined serum inhibin concentrations using immuno-assays unable to distinguish dimeric inhibin-A from inhibin-B isoforms. Inhibin-A and inhibin-B immuno-assays were used to investigate concentrations in cyclic mares, young and old (6 vs 19 years old, respectively) mares following hemi-ovariectomy, mares during pregnancy and in mares with confirmed granulosa cell tumors (GCTs). Mares with inter-ovulatory intervals of 26 days had ovulatory peaks of inhibin-A averaging $80 \mathrm{pg} / \mathrm{mL}$ with a mid-cycle nadir of $5 \mathrm{pg} / \mathrm{mL}$. Inhibin-A and inhibin-B concentrations were highly correlated $(r=+0.79, P<0.01)$ though peak and nadir concentrations of inhibin-B were not significantly different. However, the ratio of inhibin-A to inhibin-B (A/B) changed significantly through the cycle, highest at ovulation and $<1$ (more inhibin-B than $-A$ ) at mid-cycle. Two mares with grossly extended inter-ovulatory intervals demonstrated mid-cycle inhibin-A (and inhibin-B) excursions suggestive of follicular waves. Follicle-stimulating hormone was negatively correlated with inhibin-A and $-B$ concentrations in all 6 mares. Hemi-ovariectomy in young mares resulted in a significant decrease in inhibin$A$ and inhibin-B concentrations one day later $(\mathrm{P}<0.05)$ but older mares did not, suggesting a possible extra-ovarian source(s) of these hormones. Both inhibin isoforms dropped to very low levels during pregnancy $(P<0.0001)$, inhibin-A $(P<0.0001)$ more rapidly than $-B(P<0.05)$, so that inhibin- $B$ became the predominant measured form throughout most of gestation $(\mathrm{P}<0.05)$. Mares with confirmed GCTs had elevated inhibin-B concentrations more reliably than inhibin-A but neither inhibinA or -B was correlated with anti-Müllerian hormone concentrations. Collectively, concentrations of inhibin-A and $-B$ were aligned with physiological events in healthy mares, though more pronounced cyclic changes were seen with inhibin-A. Inhibin-B concentrations were significantly associated with GCTs $(P<0.01)$, inhibin-A concentrations were not. While both inhibin-A and $-B$ concentrations track physiological events such as cyclic follicular activity, only inhibin-B concentrations effectively signal ovarian neoplasia in mares.
\end{abstract}

() 2017 Elsevier Inc. All rights reserved.

\section{Introduction}

The inhibins are principally gonadal hormones that influence reproductive function by feedback at the level of pituitary where they regulate follicle stimulating hormone (FSH) secretion $[1,2]$. As a consequence, the measurement of inhibins has long been useful in the assessment of reproductive function in women [2], as well as

\footnotetext{
* Corresponding author.

E-mail address: ajconley@ucdavis.edu (A.J. Conley).
}

in the diagnosis of ovarian cancers particularly granulosa cell tumors and mucinous carcinomas [3]. Similarly, inhibins have proven to be a useful marker for ovarian function in cyclic mares [4] even if more limited in utility in other livestock species [5]. Until recently, inhibins have been the main, and most valuable, endocrine marker for ovarian granulosa-theca cell tumors (GCTs) in mares, one of the most common of all equine tumors [6]. The inhibins are dimeric glycoproteins comprised of a common $\alpha$-subunit linked to either of two $\beta$-subunits $\left(\beta_{A}\right.$ or $\left.\beta_{B}\right)$ that give rise to the two major, biologically active forms, inhibin- $A$ and inhibin- $B$, respectively. This 
involves expression of prepro-forms of the protein sub-units that undergo hetero-dimerization and processing. Though inhibin-A and inhibin-B are considered the biologically active forms, the $\alpha$ subunit can also be secreted in free form and can be recognized in some assays [7]. Consequently, detection of each of these forms in reproductively normal individuals or in disease states is complex, in part because antisera used in assay development can lack specificity. Such is the case in studies conducted in horses. Most prior studies on the concentrations of inhibins in mares and stallions have utilized assays that were unable to distinguish between the different dimeric forms that can exist in the circulation for lack of specificity for one or other subunit [4,8-11].

Given the difficulty in measuring and monitoring intact inhibin$A$ and inhibin-B, and in the absence of purified equine inhibin of any type, it has only been possible to speculate on which form is likely more relevant in the horse physiologically or as a marker of disease. Assays capable of detecting and distinguishing inhibin-A and inhibin-B specifically might prove useful in better understanding ovarian physiology of mares and prove useful in equine reproductive diagnostics. Therefore, studies were conducted to investigate whether or not assays with apparent specificity for inhibin-A and inhibin-B could detect these isoforms in the mare. Patterns of secretion were examined in cyclic mares to determine which isoform might predominate and how concentrations change. Inhibin-A and inhibin-B concentrations were also investigated in samples from mares before and after hemi-ovariectomy which was conducted as part of an on-going study into effects of surgically halving follicle reserve on ovarian hormone secretion. These mares underwent a second surgery subsequently to remove the remaining ovary providing a baseline for ovariectomized mares. Inhibin-A and $-B$ concentrations were also investigated in pregnant mares throughout gestation. Collectively, these data established normal concentrations in multiple reproductive states. Lastly, the utility of existing immuno-assays for inhibins for the diagnosis of GCTs in mares has been confirmed multiple times [6], but the relative value of measuring inhibin-A and inhibin-B specifically in blood has not been explored.

Herein we report the results of studies in mares re-examining changes in concentrations of inhibins using assays developed to detect inhibin-A, inhibin-B and "total" inhibins. The current studies included observations on changes in inhibin-A and $-B$ in cyclic mares (Experiment 1), in young and old mares following hemiovariectomy (Experiment 2), during gestation in pregnant mares (Experiment 3) and in sera from mares with confirmed GCTs submitted for diagnostic testing to the Clinical Endocrinology Laboratory at the University of California, School of Veterinary Medicine, Davis, CA. The results provide confidence in the relative diagnostic value of these new assays, and offer new insight into the patterns of secretion under different physiological conditions in mares.

\section{Materials \& methods}

3.1 Animals: Procedures were approved by the University of California, Davis Institutional Animal Care and Use Committee and by the Brazilian National Committee of Control in Animal Experimentation - CONCEA at the São Paulo State University (CEUA protocol 27/2016).

\subsection{Experimental design}

In Experiment 1, 6 light horse mares ( $7 \pm 1$ year old) of mixed breeding were monitored daily in the late fall by rectal palpation and ultrasound imaging to determine the day of ovulation and bled daily through the subsequent cycle by jugular venipuncture until ovulation was detected again. Serum was separated and stored at $-20^{\circ} \mathrm{C}$ until assayed. In Experiment 2, a group of younger mares $(6 \pm 1$ year old, $n=6)$ and older mares $(19 \pm 1$ year old, $n=6)$ were hemi-ovariectomized through a flank incision under sedation (detomidine, $20 \mu \mathrm{g} / \mathrm{kg}$ ) and local anesthesia induced by local infiltration with lidocaine. The side of hemi-ovariectomy was chosen at random as was the stage of cyclicity when surgery was performed and the side from which the ovary was removed. Consequently, there were seven mares ( 4 young, 3 old) in the luteal phase (based on progesterone concentration, data not shown) at the time of surgery, and five ( 2 young, 3 old) that were not in the luteal phase at the time of surgery all of which ovulated in the two weeks after hemi-ovariectomy. An incision was made over the lumbar fossa and muscle tissues separated bluntly to gain access to the peritoneal cavity. The ovarian pedicle was clamped and ligated with vicryl and the ovary removed. The skin incision was closed with Braunamid suture. After surgery, mares were treated with Flunixin meglumine (Banamine, $1,1 \mathrm{mg} / \mathrm{kg}$ every $12 \mathrm{~h}$ for 3 days), ceftiofur (Excede $6.6 \mathrm{mg} / \mathrm{kg}$, repeated $96 \mathrm{~h}$ later) tetanus anti-serum. Mares were examined daily and a jugular blood sample was drawn each day for two weeks following unilateral ovariectomy. A second surgery was performed subsequently a variable number of weeks later using the same procedure on the opposite flank to remove the remaining ovary, and a final blood sample taken at least two weeks later. As in Experiment 1, serum was collected and stored at $-20{ }^{\circ} \mathrm{C}$ until assayed. In Experiment 3, plasma from pregnant mares $(n=5)$ utilized samples taken in a prior study into circulating steroids during equine gestation, from day 0 (ovulation) to gestation day 330 , as reported elsewhere [12,13]. All pregnancies were normal and live, healthy foals were delivered without complications of any sort. In addition, studies incorporated serum samples $(n=44)$ submitted to the Clinical Endocrinology Laboratory, University of California, Davis, for suspected granulosa-theca cell tumor (GCT) that was subsequently confirmed by histopathology or gross lesions found on ovaries removed at surgery. All samples were assayed for inhibin using an established radio-immunoassay (RIA) as described below. A subset of samples was also assayed for antiMüllerian hormone as was requested at submission. The attending clinician was contacted later for information confirming the diagnosis of GCT by histopathology or gross appearance of cavitation on cut surface of the ovary after surgical removal.

\subsection{Western immunoblot analysis}

Immunoblot analysis was performed using the mouse monoclonal antibodies 18/16A, 20/32C and 12/9A (AI006, AI007 and AI005, respectively, Ansh Labs, USA). The 18/16A antibody is specific to inhibin $\beta$ A subunit, $20 / 32 C$ antibody is specific to inhibin $\alpha$ subunit and $12 / 9 \mathrm{~A}$ antibody is specific to activin $\mathrm{B}$ and inhibin $\beta B$ subunit. Recombinant inhibin-A and $-\mathrm{B}$ were generated from $\mathrm{CHO}$ cells stably transfected with plasmid vectors engineered to express the cDNA encoding the human inhibin- $\alpha$ subunit in tandem (as a bicistronic construct) with cDNAs encoding the human inhibin- $\beta A$ or $-\beta B$ subunits, essentially as described previously [14]. Recombinant human inhibin-A and -B secreted from these cells were purified by affinity chromatography using a CNBr-coupled monoclonal antibody (44/53A, Ansh Labs, USA) recognizing the inhibin $\alpha$ subunit. So generated, recombinant inhibin-A (AI035, Ansh Labs, USA), inhibin-B (BI043, Ansh Labs, USA), in addition to activin-B (659-AB, R \& D System, USA), were separated using $10 \%$ polyacrylamide gel electrophoresis under non-reducing and reducing conditions. Proteins were transferred to nitrocellulose membranes and incubated with the above antibodies at 1:1000 dilutions, followed by a secondary horseradish peroxidase-conjugated goat anti-mouse IgG antibody (AP503P, Millipore, USA) at 1:5000 dilution. Proteins were visualized with the ECL plus Western blotting 
detection system (Amersham Biosciences).

\subsection{Inhibin enzyme-linked immuno-sorbent assay (ELISA) assays}

\subsubsection{Inhibin ELISA design}

The inhibin-A, inhibin-B and total inhibin assays were quantitative, sandwich-type immunoassays, using monoclonal antibodies generated in female Balb/c mice against $\alpha-, \beta A$ - and $\beta B$-subunits of mature inhibin as per the procedure reported elsewhere [15].

\subsubsection{Inhibin-A ELISA}

Inhibin-A concentrations were determined using Equine/ Canine/Rodent Inhibin A ELISA reagents (AL-161, Ansh Labs LLC, Webster, TX). The assay used monoclonal antibodies specific to inhibin $\beta$ A subunit as capture (AI006, Ansh Labs LLC) and inhibin $\alpha-$ subunit for detection (AI043, Ansh Labs LLC). The assay was calibrated to recombinant human inhibin A (AI035, 6.0-650 pg/mL) and was traceable to inhibin A Human WHO Reference Reagent 91/ 624 Version 3.0. In the first step $50 \mu \mathrm{L}$ calibrators, controls, unknown samples and $25 \mu \mathrm{L}$ each of inhibin A assay buffer A and assay buffer B (ASB-123A and ASB 123B, Ansh Labs LLC) were added to inhibin $\beta A$ subunit antibody coated microtiter wells $(1 \mu \mathrm{g} /$ well $)$ and incubated for $2 \mathrm{~h}$. After the first incubation and washing, the wells were incubated with $100 \mu \mathrm{L}$ biotinylated inhibin $\alpha$-subunit antibody (1/10,000 dilution) for $2 \mathrm{~h}$. After the second incubation and washing, the wells were incubated with $100 \mu \mathrm{L}$ streptavidin horseradish peroxidase conjugate (SHRP, 1/30,000 dilution) for 30 mins. After the third incubation and washing step, the wells were incubated with $100 \mu \mathrm{L}$ substrate solution (TMB) for 10 mins.

\subsubsection{Inhibin-B ELISA}

Inhibin $B$ concentrations were determined using Equine/Canine/ Rodent Inhibin B ELISA reagents (AL-163, Ansh Labs LLC). The assay used monoclonal antibodies specific to inhibin $\beta B$ subunit as capture (AI005, Ansh Labs LLC) and inhibin $\alpha$-subunit as detection (AI043, Ansh Labs LLC). Recombinant human inhibin B (BI043, $5.0-750 \mathrm{pg} / \mathrm{mL}$ ) that was used as the calibrator was traceable to inhibin B Human WHO Reference Reagent 96/784 Version 2.0. Briefly, $50 \mu \mathrm{L}$ calibrators, controls, unknown samples and $50 \mu \mathrm{L}$ each of inhibin B assay buffer A and assay buffer B (ASB-207A and ASB-207B, Ansh Labs LLC) were added to inhibin $\beta B$ subunit antibody coated microtiter wells ( $1 \mu \mathrm{g} /$ well) and incubated for $2 \mathrm{~h}$. After the first incubation and washing, the wells were incubated with $100 \mu \mathrm{L}$ biotinylated inhibin $\alpha$-subunit antibody (1/5000 dilution) for $1 \mathrm{~h}$. After the second incubation and washing, the wells were incubated with $100 \mu \mathrm{L}$ streptavidin horseradish peroxidase conjugate (SHRP, 1/20,000 dilution) for 30 mins. After the third incubation and washing step, the wells were incubated with $100 \mu \mathrm{L}$ substrate solution (TMB) for 10 mins.

\subsubsection{Total inhibin ELISA}

Total inhibin concentrations were determined using animal Total Inhibin ELISA prototype assay reagents. The assay uses monoclonal antibodies specific to inhibin $\alpha$-subunit as capture (AI043, Ansh Labs LLC) and inhibin $\alpha$-subunit as detection (AI087, Ansh Labs LLC). The assay was calibrated to recombinant human inhibin A (AI035, 6.0-500 pg/mL). Briefly, $50 \mu \mathrm{L}$ calibrators, controls, unknown samples and $50 \mu \mathrm{L}$ each of inhibin B assay buffer $\mathrm{A}$ (ASB-123A, Ansh Labs LLC) was added to $\alpha$-subunit sub-unit antibody coated microtiter wells ( $1 \mu \mathrm{g} /$ well $)$ and incubated for $2 \mathrm{~h}$. After the first incubation and washing, the wells were incubated with $100 \mu \mathrm{L}$ biotinylated inhibin $\alpha$-subunit antibody (1/2000 dilution) for $2 \mathrm{~h}$. After the second incubation and washing, the wells were incubated with $100 \mu \mathrm{L}$ streptavidin horseradish peroxidase conjugate (SHRP, 1/38,000 dilution) for 30 mins. After the third incubation and washing step, the wells were incubated with $100 \mu \mathrm{L}$ substrate solution (TMB) for 10 mins.

\subsubsection{Inhibin ELISA development}

Reactions in all assays were stopped with addition of an acidic solution. The degree of enzymatic turnover of the substrate was determined by dual wavelength absorbance measured at $450 \mathrm{~nm}$ as the primary test filter and $630 \mathrm{~nm}$ as the reference filter. The absorbance measured was directly proportional to the concentration of recombinant inhibin in the calibrators and did not show any cross-reaction to activin $B$, activin $A$, activin $A B$, inhibin $A$, follistatins and myostatin at $1000 \mathrm{pg} / \mathrm{mL}$. The percentage spiked recovery of recombinant human inhibin-A was $98-116 \%$ and for inhibin-B was 89-103\%. Potential interfering molecules (hemoglobin, triglycerides, bilirubin and biotin) when spiked at twice their physiological concentration in serum samples yielded inhibin concentrations within $10-12 \%$ of the control levels. Linearity was verified in both follicular fluid and in serum. Sensitivities, intra- and inter-assay co-efficients of variation appear in Table 1.

\subsection{Radio-immunoassays}

\subsubsection{Inhibins were determined by RIA essentially as previously} described and validated [16,17]

Inhibin from bovine follicular fluid (bINH-I-90/1; Robertson, Monash University, Clayton, Victoria, Australia) was used for iodination, and standards were derived from dilutions of equine follicular fluid calibrated against bovine inhibin protein, which ranged from 0.15 to $10 \mathrm{ng} / \mathrm{mL}$. The primary antibody was raised in rabbits against 31-kDa bovine inhibin (rAs, \#1989; Robertson, Monash University, Clayton, Victoria, Australia). Standards $(100 \mu \mathrm{L})$, controls $(200 \mu \mathrm{L})$, or serum samples $(200 \mu \mathrm{L})$ were pipetted into tubes. Standards and control serum received $100 \mu \mathrm{L}$ buffer $(0.04 \mathrm{M}$ sodium phosphate, $\mathrm{pH} 7.4 ; 0.01 \mathrm{M}$ disodium EDTA; $0.9 \%$ sodium chloride,; 0.1\% BSA), and non-specific binding (NSB) tubes received $200 \mu \mathrm{L}$ of buffer only. Standard tubes also received $100 \mu \mathrm{L}$ gelding serum. Each tube then received $100 \mu \mathrm{L}$ of antibody (1/2000 dilution) and $100 \mu \mathrm{L}$ of tracer $(20,000 \mathrm{cpm})$ and were incubated overnight at room temperature. On the second day of the assay, $1 \mathrm{~mL}$ of goat-anti-rabbit antibody (1/250 dilution) was added to each tube. After $1.5 \mathrm{~h}$ of incubation at room temperature, tubes were centrifuged at $3210 \times \mathrm{g}$ for $30 \mathrm{~min}$ at $10^{\circ} \mathrm{C}$. Supernatants were aspirated and the radioactive pellets counted by a gamma counter. The standard curve ranged from 0.15 to $10 \mathrm{ng} / \mathrm{mL}$, the sensitivity of the assay was $0.06 \mathrm{ng} / \mathrm{mL}$ and the intra- and inter-assay coefficients of variation were $7.1 \%(n=6)$ and $6.0 \%(n=6)$, respectively.

\subsubsection{Follicle stimulating hormone (FSH)}

Concentrations of FSH were determined using a previously validated RIA [16], with slight modifications. Highly purified

Table 1

Sensitivities, and intra- and inter-assay co-efficients of variation (from $n=36$ determinations at each of two different concentrations) for inhibin-A, inhibin-B and total inhibin ELISAs.

\begin{tabular}{llll}
\hline Detected analyte & Assay sensitivity & \multicolumn{2}{l}{$\begin{array}{l}\text { Co-efficients of variation } \\
(\mathrm{n}=36)\end{array}$} \\
\cline { 3 - 4 } \cline { 3 - 4 } & & Intra-assay & Inter-assay \\
\hline Inhibin- $\mathrm{A}(74 \mathrm{pg} / \mathrm{ml})$ & $2.3 \mathrm{pg} / \mathrm{ml}$ & $3.2 \%$ & $2.8 \%$ \\
Inhibin-A $(204 \mathrm{pg} / \mathrm{ml})$ & & $8.5 \%$ & $3.5 \%$ \\
Inhibin-B $(67 \mathrm{pg} / \mathrm{ml})$ & $2.3 \mathrm{pg} / \mathrm{ml}$ & $4.6 \%$ & $3.9 \%$ \\
Inhibin-B $(203 \mathrm{pg} / \mathrm{ml})$ & & $6.3 \%$ & $3.6 \%$ \\
Total inhibin $(70 \mathrm{pg} / \mathrm{ml})$ & $6.4 \mathrm{pg} / \mathrm{ml}$ & $5.8 \%$ & $9.3 \%$ \\
Total inhibin $(247 \mathrm{pg} / \mathrm{ml})$ & & $5.6 \%$ & $3.5 \%$ \\
\hline
\end{tabular}


pituitary derived equine FSH (e265B, Papkoff, UC Davis, CA) was used for standards (ranging from 0.25 to $64 \mathrm{ng} / \mathrm{mL}$ ) and for iodination. The primary antibody was LSU 3D-2 anti-oFSH from Dr. D.L. Thompson, LSU, Baton Rouge LA, used at a 1:20,000 dilution. One hundred $\mu \mathrm{L}$ of standard, control, or serum were added to tubes along with $150 \mu \mathrm{L}$ antibody (except to total counts and NSB tubes), and incubated overnight at room temperature. On day 2, tracer $(20,000 \mathrm{cpm} / 50 \mu \mathrm{L})$ was added to all tubes, and tubes were incubated for 3 days at $4{ }^{\circ} \mathrm{C}$. On the fifth day, $100 \mu \mathrm{L}$ of a $1.0 \%$ normal rabbit serum (Sigma -7523 ) and $1 \mathrm{~mL}$ of a 1:100 dilution of goatanti-rabbit antibody (Equitech-Bio GARG-500) in 5\% polyethylene glycol were added to each tube. After incubation for $2 \mathrm{~h}$ at room temperature, tubes were centrifuged at $1430 \times \mathrm{g}$ at $10^{\circ} \mathrm{C}$ for $20 \mathrm{~min}$. Supernatants were poured off and the pellets counted in a gamma counter. The sensitivity of the assay was $0.5 \mathrm{ng} / \mathrm{mL}$ and the intraand inter-assay coefficients of variation were $6.25(n=6)$ and $6.5 \%$ $(\mathrm{n}=3)$, respectively.

\subsection{Anti-Müllerian hormone $(A M H)$}

AMH concentrations were determined using Equine AMH ELISA reagents (AL-115, Ansh Labs LLC) essentially as recommended by the manufacturer. The AMH ELISA is a quantitative 3 step sandwich type immunoassay. In the first step $50 \mu \mathrm{L}$ of calibrators, controls, unknown samples and $50 \mu \mathrm{L}$ of assay buffer (ASB-113) were added to antibody coated microtiter wells and incubated for $2 \mathrm{~h}$ at $600 \mathrm{rpm}$ on a plate shaker. After the first incubation and washing, the wells were incubated with $100 \mu \mathrm{L}$ of a second, biotinylated $\mathrm{AMH}$ antibody (BCR-115) for $1 \mathrm{~h}$ on a plate shaker. After the second incubation and washing, the wells were incubated with $100 \mu \mathrm{L}$ streptavidin horseradish peroxidase conjugate (SAR-115) for 30 mins on a plate shaker. After the third incubation and washing step, the wells were incubated with $100 \mu \mathrm{L}$ TMB chromagen solution (TMB-100) and shaken for 8 mins. The reaction was stopped with addition of $0.2 \mathrm{M}$ sulfuric acid (stopping solution). Substrate turnover was determined by dual wavelength absorbance at $450 \mathrm{~nm}$ (primary test filter) and $630 \mathrm{~nm}$ (reference filter) on a Molecular Devices VersaMax ELISA plate reader (Sunnyvale, CA, USA). The standard curve ranged from 0.063 to $15.3 \mathrm{ng} / \mathrm{mL}$, the intra- and inter-assay co-efficients of variation were $2.1(n=6)$ and $6.2 \%(n=6)$, respectively, and the sensitivity of the assay was $0.05 \mathrm{pg} / \mathrm{mL}$.

\subsection{Data analysis}

Statistical analysis utilized Mixed Model procedures (SAS, Raleigh NC). Main effects of time (Expt 1) and time and age (Expt 2) were included in repeated measures analyses. Both linear and quadratic effects over time were examined using General Linear Models procedures in SAS. Comparisons between days were made by orthogonal contrasts and/or paired T-tests, and Pearson's correlation co-efficients were estimated amongst hormones in each experiment using the Proc Corr procedure. The pregnancy data was examined for linearity using Regression Model procedures in SAS and comparisons between inhibins during pregnancy were made using Mixed Model procedures and orthogonal contrasts. Differences in detection of confirmed GCTs among inhibin-A, inhibin-B and the inhibin RIAs were evaluated by Chi-square analysis and Pearson's correlation co-efficients were estimated using Proc Corr. Data were log transformed for normality when necessary.

\section{Results}

Supernatant from cells expressing inhibin-A investigated using monoclonal antibody specific for the inhibin $\beta A$ subunit (\#A1006,
Fig. 1A) detected a single band between 10 and $15 \mathrm{kDa}$ under reducing conditions with a faint band at $50 \mathrm{kDa}$. Under nonreducing conditions, a major band was recognized slightly above $25 \mathrm{kDa}$ as well as a faint band at $50 \mathrm{kDa}$ and another between 20 and $25 \mathrm{kDa}$. The monoclonal antibody specific for the inhibin $\alpha$ subunit (\#A1007, Fig. 1B) detected a single band between 15 and $20 \mathrm{kDa}$ under reducing conditions and a single band slightly above $25 \mathrm{kDa}$ under non-reducing conditions. The $\beta \mathrm{B}$ monoclonal antibody (\#A1005, Fig. 1C) detected a major band between 10 and $15 \mathrm{kDa}$ and minor band around $50 \mathrm{kDa}$ under reducing conditions. Under non-reducing conditions there was a major band detected at slightly above $25 \mathrm{kDa}$ and multiple minor bands, one at around $50 \mathrm{kDa}$ and another between 20 and $25 \mathrm{kDa}$. The activin-B positive control was detected as a single band between 10 and $15 \mathrm{kDa}$ under reducing conditions and a single band at slightly above $25 \mathrm{kDa}$ under non-reducing conditions.

Changes in concentrations of inhibin-A, inhibin-B and total inhibin were monitored in mares during the estrous cycle with assays developed using these monoclonal antibodies. Of the 6 mares monitored for cyclic activity, 4 had an average interovulatory interval of $26 \pm 1$ days. There was a highly significant quadratic effect of time (days between ovulations) on inhibin-A concentrations $(P<0.0001)$ in these 4 mares. On average, inhibin-A concentrations dropped 8-fold from a peak of $80.3 \pm 28.7 \mathrm{pg} / \mathrm{mL}$ around the time of ovulation to a nadir of less than $10 \mathrm{pg} / \mathrm{mL}$ on day 12 of the cycle $(\mathrm{P}<0.05)$, increasing again to $91.4 \pm 16.9 \mathrm{pg} / \mathrm{mL}$ on day $19(\mathrm{P}<0.01)$ in association with the next ovulation (Fig. 2). Although a similar pattern was seen for inhibin-B, and concentrations of inhibin-A and $-\mathrm{B}$ were highly correlated $(\mathrm{r}=+0.79, \mathrm{P}<0001)$, the magnitude of change from ovulation to mid-cycle $(46.2 \pm 20.7$ and $15.1 \pm 4.1 \mathrm{pg} / \mathrm{mL}$, respectively; Fig. 2) were not as great or statistically significant and there was no main effect of time $(P>0.1)$. However, there was a significant main effect of time on the ratio on inhibin-A to inhibin-B $(A / B ; P<0.0001$; Fig. 3). The ratio of $A / B$ dropped significantly from day 0 to day 11 $(P<0.05)$ and was significantly less than 1 on days 10 and 13 $(\mathrm{P}<0.01$; Fig. 3). Total inhibin concentrations also decreased from a peak around ovulation, but the variation among mares was extreme and there was no discernible increase associated with the subsequent ovulation (data not shown). Correspondingly, the cyclic changes in inhibin-A and inhibin-B were less correlated with total inhibins $(r=+0.41$ with inhibin- $A$ and $r=+0.61$ with inhibin- $B$, $P<0.0001$ ). The remaining 2 (of the 6 ) mares monitored had grossly extended inter-ovulatory intervals of 40 and 45 days and their data were analyzed separately. Both experienced multiple peaks in both inhibin-A and inhibin-B concentrations during the interval between ovulations (Fig. 4). These peaks of inhibin-A and inhibin-B appeared interspersed between peaks of FSH (Fig. 4) and, as with the mares with more normal cycle lengths, this was supported by a negative correlations between FSH and both the inhibin- $\mathrm{A}(\mathrm{r}=-0.49$ and $-0.31, \mathrm{P}<0.05)$ and inhibin- $\mathrm{B}(\mathrm{r}=-0.49$ and $-0.29, \mathrm{P}<0.05$ ) for the mares with the 40 and 45 day cycles, respectively.

There were no age-related differences $(P>0.1)$ in concentrations of either inhibin-A $(66.0 \pm 26.0$ vs $45.8 \pm 10.1 \mathrm{pg} / \mathrm{mL}$, young and old mares, respectively) or inhibin-B $(27.9 \pm 6.0$ vs $28.2 \pm 6.2 \mathrm{pg} / \mathrm{mL}$, young and old mares, respectively) before surgery in Experiment 2 (Fig. 5). Similarly, there was no overall main effect of time or age on either inhibin-A or -B. However, hemiovariectomy affected inhibin-A and inhibin-B concentrations in young mares acutely. In these mares, inhibin-A decreased by one third to $44.0 \pm 18.9 \mathrm{pg} / \mathrm{mL}$ on the day after surgery $(\mathrm{P}<0.05)$ and to a nadir of $32 \pm 6 \mathrm{pg} / \mathrm{mL}$ on day 4 . Inhibin-B also declined in young mares by $50 \%$ following hemi-ovariectomy to $14.3 \pm 2.3 \mathrm{pg} / \mathrm{mL}$ one day later $(\mathrm{P}<0.05)$, after which it slowly returned to pre-surgical 


\section{R NR}

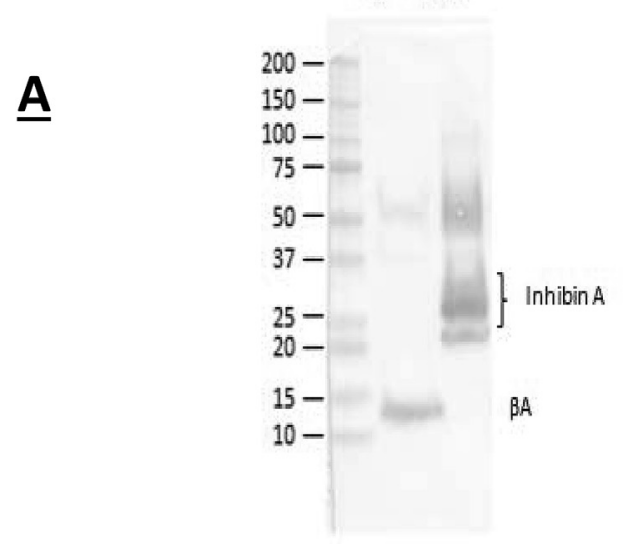

\#A1006
R NR

$\underline{B}$

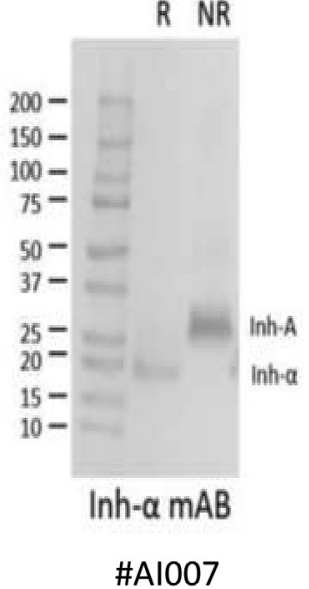

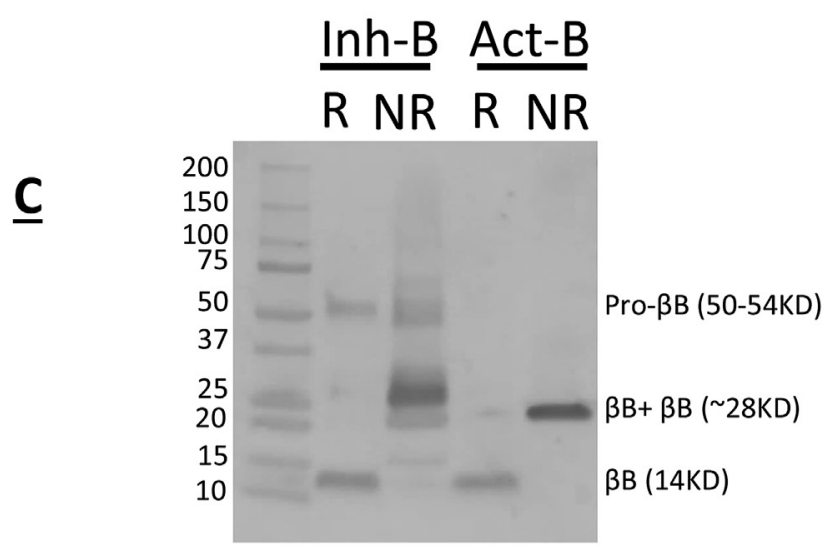

12/9A (AI005)

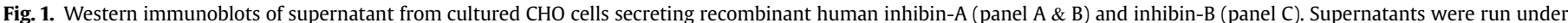

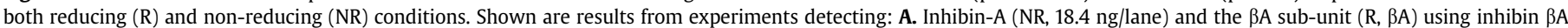

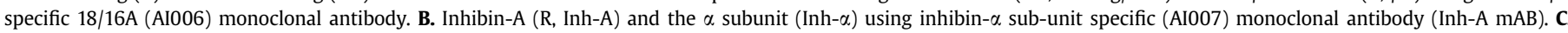

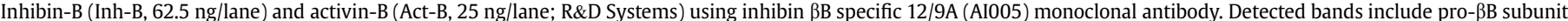
(50-54kD) of inhibin-B (R and NR, Inh-B), dimeric $\beta B$ (NR, Inh-B; NR, Act-B, 28kD) and monomeric $\beta B$ (R, Inh-B and Act-B, 14kD) fragments.

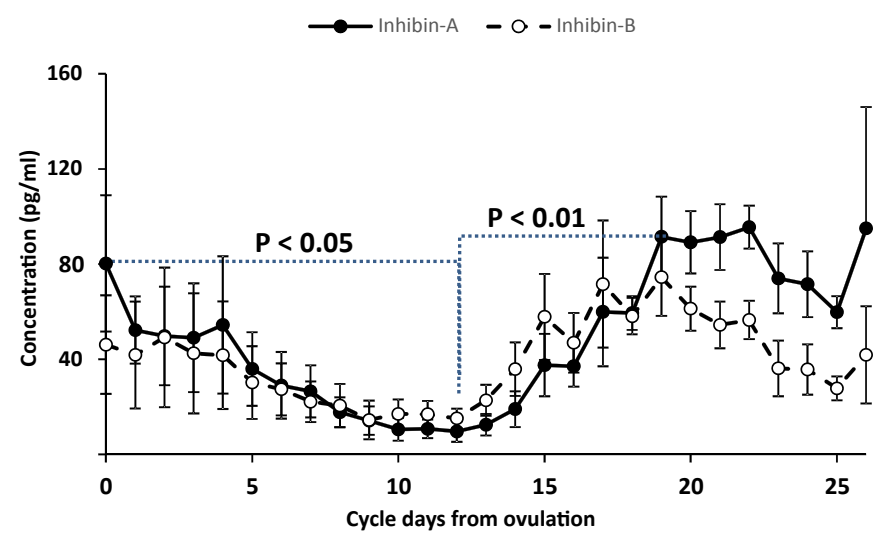

Fig. 2. Daily concentrations (pg/mL) of inhibin-A (solid line) and inhibin-B (dashed line) in serum from cyclic mares $(n=4)$ with a mean inter-ovulatory interval of $26 \pm 1$ days. Differences in concentrations of inhibin-A between day 0 and $12(\mathrm{P}<0.05)$, and between day 12 and 19 of the cycle are as indicated $(P<0.01)$. Shown are means \pm standard errors of the mean.

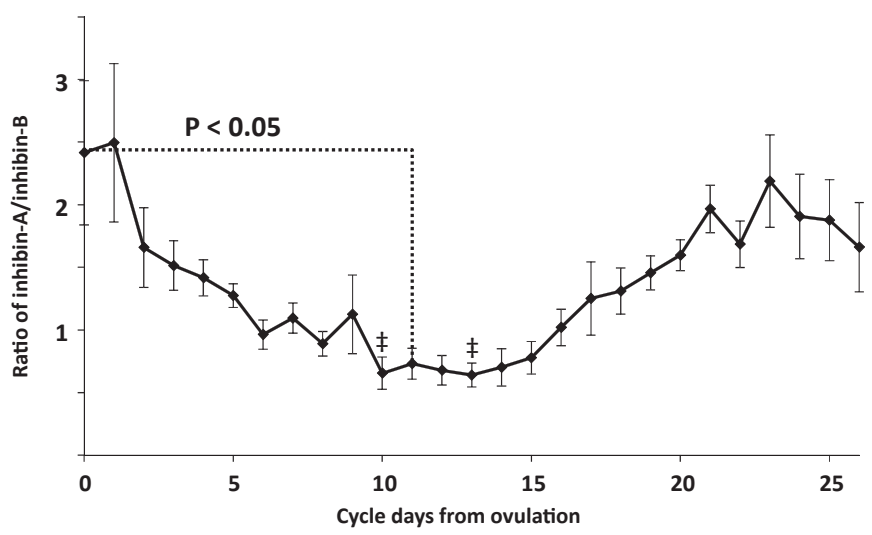

Fig. 3. Ratio of the concentrations of inhibin-A and inhibin-B $(A / B)$ in serum from cyclic mares $(n=4)$ with a mean inter-ovulatory interval of $26 \pm 1$ days. There was a significant main effect of day $(\mathrm{P}<0.0001)$, the ratio on day 11 was lower $(\mathrm{P}<0.05)$ than day 0 and the ratios on day 10 and day 13 were significantly less than 1 (inhibin-B was higher than inhibin-A on these days; $\ddagger \mathrm{P}<0.01$ ). 

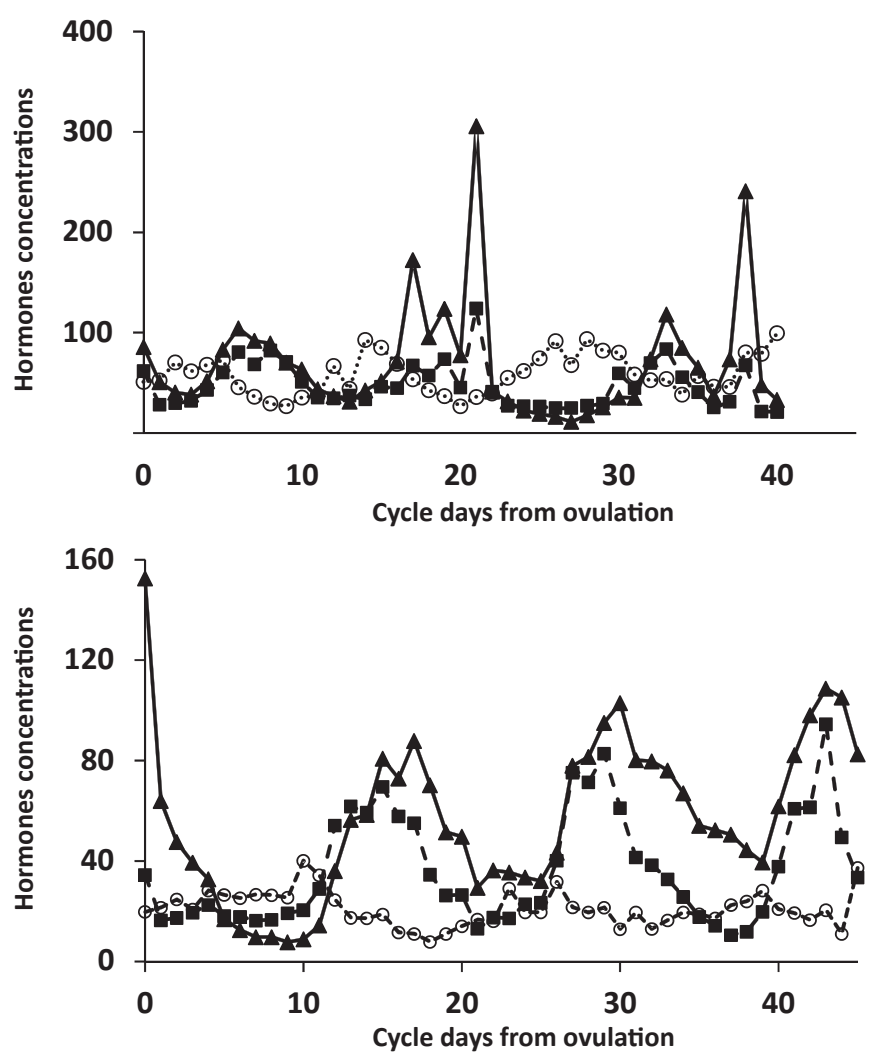

Fig. 4. Daily concentrations of inhibin-A (solid line, triangles, $\mathrm{pg} / \mathrm{mL}$ ), inhibin-B (dashed line, squares, $\mathrm{pg} / \mathrm{mL}$ ) and FSH (dotted line, open circles, $\mathrm{ng} / \mathrm{mL} \times 5$ ) in serum from 2 mares with grossly extended inter-ovulatory intervals of 40 and 45 days.

levels by day 10 (Fig. 5). In contrast to young mares, there was no decrease in inhibin-A or -B or concentrations after surgery in the older mares. Though few of the mares were cycling at the time of the second surgery, removal of the remaining ovary decreased inhibin-A from $10.7 \pm 3.9$ to $2.4 \pm 0.3 \mathrm{pg} / \mathrm{ml}$, and inhibin-B from $13.5 \pm 3.5$ to $6.2 \pm 1.4 \mathrm{pg} / \mathrm{ml}$.

Concentrations of inhibin-A and inhibin-B both decreased significantly during gestation $(\mathrm{P}<0.0001)$. The decline in inhibin-A concentrations was most dramatic between GD30 and GD60 (Fig. 6, $\mathrm{P}<0.0001$ ) and maintained a steady low baseline for the remainder of pregnancy. Inhibin-B concentrations declined more gradually to a nadir around GD200 $(P<0.05)$. Though inhibin-A concentrations were higher on day 0 and day 30 of gestation, and concentrations of both isoforms were generally very low, inhibin-B concentrations exceeded those of inhibin-A from gestation day 60 until term (Fig. 6, P $<0.0001$ ).

The standards used in the inhibin RIA, when assayed for inhibinA and inhibin-B, detected on average 9.5- and 19.1-fold less, respectively, than was detected by the polyclonal antisera in the RIA, based on the slopes of the regression curves generated $\left(R^{2}>0.99\right.$, not shown). In the samples submitted for a suspected GCT, and therefore assayed for inhibin using the RIA, there was a strong positive linear correlation between the estimates from the RIA and the immuno-assays for inhibin- $\mathrm{A}(\mathrm{r}=+0.74, \mathrm{P}<0.001)$ and inhibin- $\mathrm{B}(\mathrm{r}=+0.68, \mathrm{P}<0.001)$. However, there was no significant correlation between AMH and the either inhibin-A or inhibin-B concentrations $(P>0.3)$. The diagnostic potential for using inhibin-A and/or inhibin-B in suspected cases of GCTs was evaluated using the mean +3 standard deviations calculated on the data from mares in experiments 1 and 2 as reference ranges. So calculated, the upper limit of normal was $160 \mathrm{pg} / \mathrm{mL}$ for Inhibin-A and
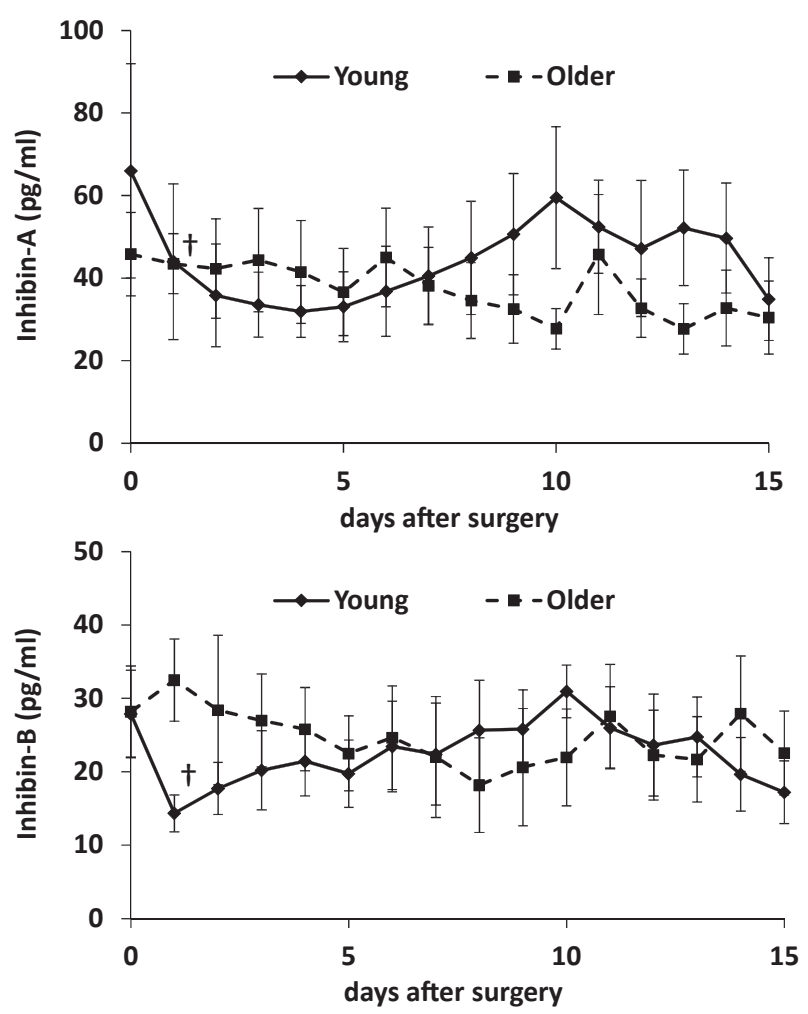

Fig. 5. Daily serum concentrations $(\mathrm{pg} / \mathrm{mL}$ ) of inhibin-A (upper panel) and inhibin-B (lower panel) in young $(\mathrm{n}=6,6 \pm 1$ year of age, solid line) and older $(\mathrm{n}=6,19 \pm 1$ year of age, dashed line) mares before (day 0 ) and after hemi-ovariectomy (days $1-15$ ). Shown are means \pm standards errors of the mean. $\dagger$ Indicates difference between presurgical (day 0 ) and post-surgical (day 1 ) concentrations in young mares only, $\mathrm{P}<0.05$.

$100 \mathrm{pg} / \mathrm{mL}$ for inhibin-B. With these diagnostic criteria, inhibin-B detected $26 / 34$ (76\%) of confirmed cases of GCTs compared with $24 / 34$ (71\%) detected using the clinical inhibin RIA and 10/34 (29\%) for inhibin-A. The inhibin-B assay was comparable to the inhibin RIA in detecting GCTs $(P>0.5)$ and both were significantly better than was inhibin-A $(P<0.001)$.

\section{Discussion}

To the best of the authors' knowledge, this is the first study reporting serum concentrations of inhibin-A and inhibin-B in mares. Results reported provide biochemical and biological validation

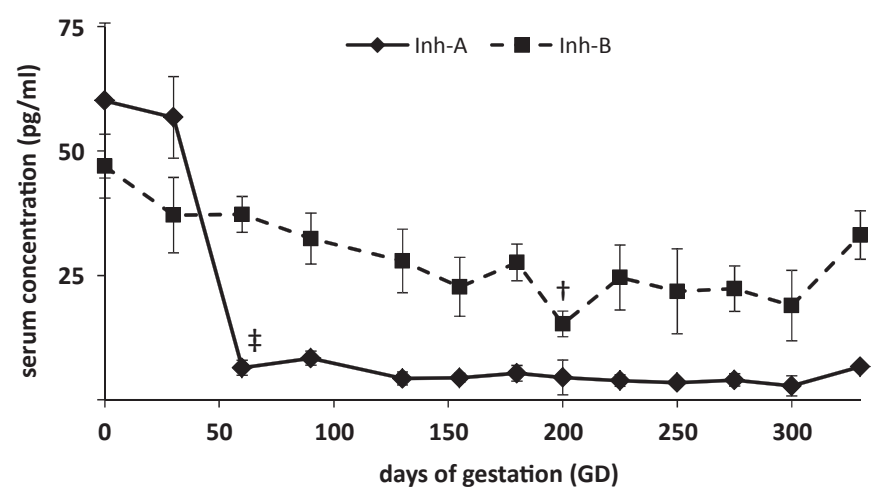

Fig. 6. Concentrations (pg/ml) of inhibin-A (solid) and inhibin-B (dashed) in plasma of mares $(n=5)$ bled throughout gestation. $\ddagger$ Difference between GD30 and 60 for inhibin-A, $\mathrm{P}<0.0001$. †Difference between GD0 and 200 for inhibin-B, $\mathrm{P}<0.05$. 
for immuno-assays using monoclonal antibodies specifically detecting inhibin $\beta \mathrm{A}, \beta \mathrm{B}$ and $\alpha$-subunits, and thereby inhibin- $\mathrm{A}$ and inhibin-B in sera from cyclic $(n=6)$ and hemi-ovariectomized mares $(n=12)$, pregnant mares $(n=5)$, as well as mares with confirmed GCTs $(n=44)$. Inhibin concentrations in cyclic mares were first measured using a RIA with polyclonal antisera raised against a peptide fragment of the porcine inhibin $\alpha$-subunit that was also used for preparation of the tracer [8]. Consequently, the assay did not distinguish free $\alpha$-sub-unit from dimeric forms. Inhibin concentrations did not vary dramatically through the cycle, a peak at ovulation was not obvious for instance, but inhibin was negatively correlated with FSH [8]. Several other investigators employed assays developed using purified bovine inhibin as the antigen for raising antisera, labeling tracer and standards $[4,9-11,18]$. These assays also lack isoform or sub-unit specificity and results were reported as inhibins. For instance, peak inhibins concentrations at ovulation were reported to average $>540 \mathrm{pg} / \mathrm{mL}$, declining by $50 \%$ to mid-luteal phase concentrations of around $210 \mathrm{pg} / \mathrm{mL}$ and were also negatively correlated with FSH [4]. Some have suggested this may be associated with uptake of inhibin by follicular fluid released into the peritoneal cavity at ovulation [10]. In any case, similar findings by others confirmed these circulatory patterns $[9,11]$. The current data are generally consistent with those reported previously but extend them, providing evidence that inhibin-A concentrations are higher than inhibin-B they peak at ovulation. Both then decrease during the mid-luteal phase and at their nadir inhibin-B concentrations predominate over inhibin-A. However, more dynamic fluctuations in concentrations were detected in this study than previously ( $>8$-fold nadir to peak for inhibin- $A,>3$-fold for inhibin-B), perhaps because the assays employed are more isoform specific. The mares in this study did exhibit long inter-ovulatory intervals. Those with an interval of 26 days were at the very extreme of that considered normal for mixed breed light horses [19] though these mares were normal by all clinical measures. Observations were insufficient to determine if cycle length in these mares was associated with diestrous ovulations [20]. This seems unlikely in view of the fact that there were no inter-ovulatory increases in inhibin-A or inhibin-B concentrations detected in those mares, but may well have been the case for the other 2 mares with 40 and 45 day inter-ovulatory intervals. Regardless of whether or not the cyclic changes observed in the majority of mares studied here are representative of what could be regarded as "normal" cycles, inhibin-A exhibited ovulation-related peaks and a nadir at mid-cycle that were distinct from, but still highly correlated with, inhibin-B.

As noted above, few studies have been conducted to investigate differences that might exist in circulating concentrations of dimeric inhibin-A and inhibin-B in horses, due to a lack of reagents with sufficient sub-unit specificity for the equine hormones. To date, expression of the inhibin- $\beta \mathrm{B}$ sub-unit in equine ovaries has been investigated by immuno-histochemistry but available data are somewhat contradictory. The inhibin $\beta \mathrm{B}$ sub-unit was not detectable in any of 4 GCTs in one study [21] but was reportedly expressed along with the $\alpha$-sub-unit and the $\beta$ A sub-unit in both theca and granulosa of equine follicles by others [9]. Inhibin-A and inhibin-B were detected in equine follicular fluid, along with other growth factors, using specific ELISAs but systemic concentrations were not reported [22]. Follicular fluid concentrations of inhibin-A were observed to increase earlier in follicular development (around the time of deviation) than did inhibin- $B$ which is consistent with the increasing concentration of inhibin- $A$ and increasing ratios of $A / B$ around ovulation. This suggests a level of differential regulation of the inhibin-A and -B dimeric forms and possibly different physiological roles. It would appear that dominant follicles secrete more inhibin-A than inhibin-B. Inhibin-B concentrations were also detected in systemic blood from 4 mares with GCTs in a prior study [23] using a sandwich ELISA for that isoform but inhibin-A concentrations were not investigated or not reported. Three of these mares were re-examined after surgical removal of the tumor, all of which exhibited a (variable) decline. In any case, we believe the current data are the first relating to circulating inhibin-B concentrations in cyclic mares. The lack of correlated changes in total inhibins may explain why previous, less specific assays did not detect such marked cyclic patterns as those reported here and is consistent with greater specificity shown in the current assays developed for inhibin-A and -B.

A significant decline in inhibin-A and inhibin-B was also observed one day after hemi-ovariectomy in young mares, providing additional biological validation for these assays in terms of supporting an ovarian source. Inhibin- $A$ and $-B$ concentrations rebounded thereafter consistent with a rapid compensatory ovarian hypertrophy response, likely associated with a reestablishment of follicle numbers and/or size. However, the postsurgical decrease was observed only in young (6 year old) mares, not in older (19 year old) mares. In young mares, both inhibin-A and inhibin-B concentrations recovered, though the time courses were somewhat different. A more rapid decline and recovery of inhibin-B than inhibin-A in the young hemi-ovariectomized mares could reflect differences in half-life or it might otherwise reflect differential regulation and rates of recovery of follicle populations of different sizes. The lack of specific assays in the past has not allowed the half-life of inhibin-A and inhibin-B to be assessed and compared in horses but such studies are now possible. Analysis of appropriately timed longitudinal samples taken following complete gonadectomy will be required to properly address that issue [1].

The reasons for the lack of change in inhibin-A and -B concentrations following hemi-ovariectomy in older mares are unclear at this time, but it suggests the possibility that inhibins are secreted by tissues in mares other than the ovaries. Using the Monash reagents and the clinical assay, as reported here, inhibin secretion by adrenal cortical tumors, as well as cases of adrenocortical hyperplasia, was detected in neutered dogs [24]. This is consistent with reports showing inhibin sub-unit expression and inhibin secretion by adrenal tissues of other species including humans [25]. These data would seem to provide a rationale for further studies investigating the secretion of inhibins by adrenal or perhaps other extra-gonadal tissues in horses, and how this might influence cyclicity and fertility, especially in aging mares. Additionally, inhibin-A and $-B$ concentrations in the 2 mares with extended inter-ovulatory intervals provided evidence that follicle waves may be monitored in systemic blood by inhibin concentrations in this species. This also appears to be a novel and potentially significant finding which is currently being further investigated with more careful, frequent and detailed clinical observation. While AMH is considered a useful biomarker for ovarian reserve [26-28], it is not subject to pituitary feedback and secretion is limited to the peri-antral stages of follicular growth when gonadotropic responsiveness develops [26]. In this regard, inhibin-A or inhibin-B may prove to be more valuable biomarkers of the potential for ovarian response to gonadotropic stimulation, if not in mares then perhaps in other species. In any case, the differences in response to hemi-ovariectomy in the younger compared with the older mares suggests that inhibin-A and inhibin-B may also provide some insight into ovarian aging and the associated decline in fertility in this species. Given the more dynamic changes in inhibin-A concentrations during the equine estrous cycle, the decline that follows hemi-ovariectomy and the higher negative correlation with concentrations of FSH, inhibin-A may be more significant as a biomarker or physiological regulator of the ovarian-pituitary axis in the horse. 
Inhibin-A and inhibin-B concentrations decreased generally during gestation in mares and, as with fluctuations seen during cyclicity, inhibin-A decreased far more than did inhibin-B. The more marked decline in inhibin-A concentrations than inhibin-B reversed the ratio of $A / B$ seen at ovulation (day 0 ) and at 30 days of gestation so that, although still extremely low, inhibin-B concentrations were significantly higher than inhibin-A at GD 60 and remained so for the rest of pregnancy. These data contrast those reported previously in pregnant mares [29] where an increase in immuno-reactivity was seen during gestation coinciding with the growth of the fetal gonads. Inhibin concentrations in that study were measured using an immuno-assay that did not discriminate different possible forms of the hormone and might have included free $\alpha$-sub-unit. The source (fetal or maternal) was unclear, but the hormone detected was biologically inert [29]. The reason for the discrepancy between studies is unknown but it could relate once again to the greater specificity of the assays utilized here. In any case, the eventual dominance of inhibin-B concentrations over inhibin-A observed here was somewhat similar to that seen midcycle in the non-pregnant mares. If the origin of inhibin- $A$ and inhibin-B in pregnant mares is the maternal ovaries, then secretion would likely reflect follicle populations and changes in them with advancing gestation. Though occurring relatively early in gestation, if the decline in inhibin-A and $-B$ detected here still reflect secretion by the maternal ovaries, it is consistent with the disappearance of ovarian follicles and follicular activity seen in pregnant mares with advancing gestation as originally observed [30].

In contrast to the clear evidence for secretion of both inhibin-A and $-B$ by the ovary during cyclicity and early pregnancy, the current results indicate that equine GCTs secrete predominantly inhibin-B. Previous studies reported finding the inhibin- $\alpha$ sub-unit and $\beta$ A expression in GCTs $[21,31,32]$ as well as in equine follicular fluid [33]. This is consistent with the significant positive correlation between inhibin-A and inhibin-B concentrations in mares with confirmed GCTs examined here. The current data indicate quite clearly however that the secretion of inhibin-B is a far better biomarker for equine GCTs than is inhibin-A. Moreover, the secretion on inhibin-B by equine GCTs is consistent with prior reports $[9,23]$ as noted above. In contrast to findings previously reported from our laboratory [34], there was no correlation between inhibins determined by the clinical assay, or inhibin- $\mathrm{A}$ or $-\mathrm{B}$, and concentrations of $\mathrm{AMH}$ in the present case series, though inhibins and AMH are both granulosa cell products [35]. This is perhaps not surprising given the likelihood that the peak of secretion of each of these hormones occurs at different stages of follicular development. Clearly, inhibin-A and inhibin-B secretion is periodic and highly regulated in cyclic mares but there is little variation across cycles in concentrations of AMH [35], perhaps reflecting more stable population of peri-antral follicles. The lack of correlation in mares with GCTs in this series suggests these hormones provide different biological information with potentially additive value. It is of interest also that the results in mares with GCTs contrast those in women with granulosa cell tumors which do not appear to be so selective in the form of inhibins they secrete [3,15,36]. How this might relate to the differences in behavior of the tumors (in contrast to women, rarely malignant in mares even when large) or to the more common involvement of interstitial (theca-derived, androgen secreting) elements in equine GCTs [37] is unknown. Regardless, the immunoblots data and the differences in secretion of inhibin-A and inhibin-B detected in this equine case series both support the specificity of these assays for their isoform targets. Inhibin-B performed as well as the clinical assay currently used by the UC Davis Clinical Endocrinology Laboratory which recognizes multiple forms. Additional clinical data will be needed to better assess the true sensitivity of the detection of equine GCTs using this
inhibin-B assay.

In conclusion, the current data provide confidence in the ELISAs developed to detect inhibin-A and inhibin-B with specificity in horses in a physiological and (in a clinical sense) a diagnostically useful range. Furthermore, evidence is provided suggesting that inhibin-A may be more likely to be physiologically relevant (greater fluctuations during the cycle, more negatively correlated with FSH and a more rapid and marked decline during gestation) than inhibin-B in mares, but that inhibin-B is the isoform whose secretion is increased more reliably in mares with GCTs. This is of relevance for diagnosing GCTs, even in pregnant mares, but may also provide insight into the pathophysiology of this condition. Studies correlating changes in inhibin-A and inhibin-B with wellcharacterized follicular waves in mares experiencing normal and extended cycles are in progress to confirm the origins of the apparent patterns observed.

\section{Statement of potential conflict of interest}

As a potential conflict of interest, the authors acknowledge that B. Kalra, G. V. Savjani and A. Kumar are employees of Ansh Labs LLC, Webster, TX, USA, 77598, the company that developed and markets the inhibin and anti-Mullerian hormone ELISA assay platforms used in the determinations reported here.

\section{Acknowledgements}

This research did not receive any specific grant funding from agencies in the public, commercial, or not-for-profit sectors. However, the authors acknowledge the generous support of the John P. Hughes Endowment that provided partial support for these studies. The authors would also like to express their sincere gratitude to Drs. Jenny Boye and Catherine Renaudin for invaluable help in monitoring mares and collecting blood samples, and to Dr. Jan Roser who generously donated reagents used to assay FSH.

\section{References}

[1] Robertson DM, Risbridger GP, de Kretser DM. The physiology of testicular inhibin and related proteins. Baillieres Clin Endocrinol Metab 1992;6:355-72.

[2] Robertson DM. Inhibins and activins in blood: predictors of female reproductive health? Mol Cell Endocrinol 2012;359:78-84.

[3] Robertson DM, Stephenson T, Pruysers E, Burger HG, McCloud P, Tsigos A, et al. Inhibins/activins as diagnostic markers for ovarian cancer. Mol Cell Endocrinol 2002;191:97-103.

[4] Roser JF, McCue PM, Hoye E. Inhibin activity in the mare and stallion. Domest Anim Endocrinol 1994;11:87-100.

[5] Knight PG, Glister C. TGF-beta superfamily members and ovarian follicle development. Reproduction 2006;132:191-206.

[6] McCue PM, Roser JF, Munro CJ, Liu IK, Lasley BL. Granulosa cell tumors of the equine ovary. Vet Clin North Am Equine Pract 2006;22:799-817.

[7] Burger HG, Robertson DM. Editorial: inhibin in the male-progress at last, Endocrinology 1997; 138:1361-2.

[8] Bergfelt DR, Mann BG, Schwartz NB, Ginther OJ. Circulating concentrations of immunoreactive inhibin and FSH during the estrous cycle of mares. J Equine Veterinary Sci 1991;11:319-22.

[9] Nagamine N, Nambo Y, Nagata S, Nagaoka K, Tsunoda N, Taniyama H, et al. Inhibin secretion in the mare: localization of inhibin alpha, betaA, and betaB subunits in the ovary. Biol Reprod 1998;59:1392-8.

[10] Nambo Y, Nagaota K, Tanaka Y, Nagamine N, Shinbo H, Nagata S, et al. Mechanisms responsible for the increase in circulating inhin concentrations at the time of ovulation in mares. Theriogenology 2002;57:1707-17.

[11] Nagaoka K, Nambo Y, Nagamine N, Nagata SI, Tanaka Y, Shinbo H, et al. A selective increase in circulating inhibin and inhibin pro-alphaC at the time of ovulation in the mare. Am J Physiol 1999;277:E870-5.

[12] Scholtz EL, Krishnan S, Ball BA, Corbin CJ, Moeller BC, Stanley SD, et al. Pregnancy without progesterone in horses defines a second endogenous biopotent progesterone receptor agonist, 5alpha-dihydroprogesterone. Proc Natl Acad Sci U. S. A 2014;111:3365-70.

[13] Legacki EL, Scholtz EL, Ball BA, Stanley SD, Berger T, Conley AJ. The dynamic steroid landscape of equine pregnancy mapped by mass spectrometry. Reproduction 2016;151:421-30.

[14] Pangas SA, Woodruff TK. Production and purification of recombinant human 
inhibin and activin. J Endocrinol 2002;172:199-210.

[15] Lambert-Messerlian G, Steinhoff M, Kumar A, Eklund EE, Moore R. Comparison of inhibin alpha-subunit and anti-Mullerian hormone immunoreactivity in granulosa cell and mucinous ovarian tumors. Appl Immunohistochem Mol Morphol 2017;25:71-7.

[16] Jennings MW, Boime I, Daphna-Iken D, Jablonka-Shariff A, Conley AJ Colgin $\mathrm{M}$, et al. The efficacy of recombinant equine follicle stimulating hormone (reFSH) to promote follicular growth in mares using a follicular suppression model. Anim Reprod Sci 2009;116:291-307.

[17] Yoon MJ, Boime I, Colgin M, Niswender KD, King SS, Alvarenga M, et al. The efficacy of a single chain recombinant equine luteinizing hormone (reLH) in mares: induction of ovulation, hormone profiles, and inter-ovulatory intervals. Domest Anim Endocrinol 2007;33:470-9.

[18] Watson ED, Thomassen R, Steele M, Heald M, Leask R, Groome NP, et al Concentrations of inhibin, progesterone and oestradiol in fluid from dominant and subordinate follicles from mares during spring transition and the breeding season. Anim Reprod Sci 2002;74:55-67.

[19] Ginther OJ, Pierson RA. Regular and irregular characteristics of ovulation and the interovulatory interval in mares. J Equine Veterinary Sci 1989;9:4-12.

[20] Claes A, Ball BA, Scoggin KE, Roser JF, Woodward EM, Davolli GM, et al. The influence of age, antral follicle count and diestrous ovulations on estrous cycle characteristics of mares. Theriogenology 2017;97:34-40.

[21] Hoque S, Derar RI, Senba H, Osawa T, Kano K, Taya K, et al. Localization of inhibin alpha-, betaA- and betaB-subunits and aromatase in ovarian follicles with granulosa theca cell tumor (GTCT) in 6 mares. J Vet Med Sci 2003;65: $713-7$.

[22] Donadeu FX, Ginther OJ. Follicular waves and circulating concentrations of gonadotrophins, inhibin and oestradiol during the anovulatory season in mares. Reproduction 2002;124:875-85.

[23] Ellenberger C, Bartmann CP, Hoppen HO, Kratzsch J, Aupperle H, Klug E, et al. Histomorphological and immunohistochemical characterization of equine granulosa cell tumours. J Comp Pathol 2007;136:167-76.

[24] Bromel C, Nelson RW, Feldman EC, Munro CJ, Kass PH, Vico AE, et al. Serum inhibin concentration in dogs with adrenal gland disease and in healthy dogs. J Vet Intern Med 2013;27:76-82.

[25] Nishi Y, Haji M, Takayanagi R, Yanase T, Ikuyama S, Nawata H. In-vivo and invitro evidence for the production of inhibin-like immunoreactivity in human adrenocortical adenomas and normal adrenal-glands - relatively high secretion from adenomas manifesting Cushings syndrome. Eur J Endocrinol
$1995 ; 132: 292-9$.

26] Claes AN, Ball BA. Biological functions and clinical applications of antiMullerian hormone in stallions and mares. Vet Clin North Am Equine Pract 2016;32:451-64.

[27] Tal R, Seifer DB. Ovarian reserve testing: a user's guide. Am J Obstet Gynecol 2017:217(2):129-40.

[28] Mossa F, Jimenez-Krassel F, Scheetz D, Weber-Nielsen M, Evans ACO Ireland JJ. Anti-Mullerian Hormone (AMH) and fertility management in agricultural species. Reproduction 2017:154:R1-11.

[29] Nambo Y, Nagata S, Oikawa M, Yoshihara T, Tsunoda N, Kohsaka T, et al. High concentrations of immunoreactive inhibin in the plasma of mares and feta gonads during the second half of pregnancy. Reprod Fertil Dev 1996;8: 1137-45.

[30] Cole HH, Howell CE, Hart GH. The changes occurring in the ovary of the mare during pregnancy. Anat Rec 1931;49:199-209.

[31] Piquette GN, Kenney RM, Sertich PL, Yamoto M, Hsueh AJ. Equine granulosatheca cell tumors express inhibin alpha- and beta A-subunit messenger ribonucleic acids and proteins. Biol Reprod 1990;43:1050-7.

[32] Christman SA, Bailey MT, Wheaton JE, Troedssen MHT, Ababneh MM Santschi EM. Dimeric inhibin concentrations in mares with granulosa-theca cell tumors. Am J Veterinary Res 1999;60:1407-10.

[33] Bailey MT, Christman SA, Wheaton JE, Troedssen MHT, O'Brien DO, Ababneh MM, et al. Inhibin localization in equine granulosa-theca cell tumours and inhibin forms in tumour fluid. J Reproduction Fertil Suppl 2000;56: 247-55.

[34] Ball BA, Almeida J, Conley AJ. Determination of serum anti-Mullerian hormone concentrations for the diagnosis of granulosa-cell tumours in mares. Equine Vet J 2013;45:199-203.

[35] Almeida J, Ball BA, Conley AJ, Place NJ, Liu IK, Scholtz EL, et al. Biological and clinical significance of anti-Mullerian hormone determination in blood serum of the mare. Theriogenology 2011;76:1393-403.

[36] Geerts I, Vergote I, Neven P, Billen J. The role of inhibins B and antimullerian hormone for diagnosis and follow-up of granulosa cell tumors. Int J Gynecol Cancer 2009:19:847-55.

[37] Neto AC, Ball BA, Browne P, Conley AJ. Cellular localization of androgen synthesis in equine granulosa-theca cell tumors: immunohistochemical expression of 17alpha-hydroxylase/17,20-lyase cytochrome P450. Theriogenology 2010;74:393-401. 